\title{
Bitki Sekonder Metabolitlerinin Sağlık Üzerine Fonksiyonel Etkileri
}

\author{
Taha Gökmen Ülger®®, Nurcan Yabancı Ayhan²®
}

'Bolu Abant İzzet Baysal Üniversitesi, Beslenme ve Diyetetik, Bolu, Türkiye ${ }^{2}$ Ankara Üniversitesi, Beslenme ve Diyetetik, Ankara, Türkiye

Taha Gökmen Ülger, Uzm. Dyt. Nurcan Yabancı Ayhan, Prof. Dr.

Illetişim:

Uzm. Dyt. Taha Gökmen Ülger

Bolu Abant İzzet Baysal Üniversitesi, Beslenme ve Diyetetik, Bolu, Türkiye

Tel: +905321797875

E-Posta: tgulger@ankara.edu.tr

Gönderilme Tarihi : 25 Eylül 2018

Revizyon Tarihi : : 07 Mayıs 2019

Kabul Tarihi : $\quad 08$ Mayls 2019
ÖZET

Fenolik bileşikler, terpenler-steroidler, alkaloidler ve kükürtlü bileşikler olmak üzere genel olarak dört grupta sınıflandırılan sekonder bileşiklerin bazı türlerinin antiinflamatuar, hipoglisemik, hipolipidemik ve antioksidan etki göstermesi, kardiyovasküler hastalıklar ve kansere karşı koruyucu olması ve sağlık üzerine farklı birtakım olumlu etkileri bulunması dolayısıyla tıp ve eczacılık için büyük önem arz etmektedir. Bazı fenolik bileşiklerin lipoproteinlerin oksidasyonunu önleyerek, hipokolesterolemik etki göstererek, aterosklerozis riskini azaltarak, platelet agregasyonunu inhibe ederek, vasküler fonksiyonu iyileştirerek, inflamasyon ve oksidatif strese karşı koruyarak kardiyoprotektif etki gösterdiği, kükürtlü bileşikler ve flavonoidler gibi bazı sekonder bileşiklerin ise diyabete bağlı olarak görülen hiperglisemi ve bozulmuş lipid profiline karşı yararlı etkilerinin bulunduğu ve bu sayede diyabetik nöropati, diyabetik nefropati, diyabetik retinopatiye karşı koruyucu olabileceği belirtilmiştir. Bazı fenolik bileşikler ve alkaloidlerin de DNA'ya karsinojen bağlanmasını inhibe ederek, oksidatif DNA hasarına karşı koruyarak, malign dönüşümün inhibisyonuna yol açan değiştirilmiş hücre sinyallemesini normalize ederek, kanser hücresinin büyümesini ve metastatik potansiyelini inhibe ederek antikarsinojenik etki gösterdiği belirtilmiştir. Biyoreaktör teknolojisinin gelişimi ile daha fazla sayıda sekonder metabolit keşfedilmiş ve bu sayede ilaç yapımında bitki sekonder metabolitleri daha fazla kullanılmaya başlanmışıı. Fakat yalıızca hastalıkların tedavisinde değil, sağıı̆ın sürdürülmesi ve hastalıklara karşı korunmada da etkili olan sekonder metabolitlerin ekstrakte ve nutrasötik formlarından ziyade meyve ve sebzelerle birlikte doğal formlarının alınması daha yararlı olabilmektedir. Hastalıklara ilişkin tıbbi beslenme önerilerinde de fonksiyonel etkinliği bilinen sekonder metabolitlerin yoğun bulunduğu sebze ve meyvelerin önerilmesiyle hastalığın klinik seyri iyileştirilebilir. Farklı sekonder metabolitlerin hastalıklara karşı fonksiyonel etkinliğinin değerlendirileceği çalışmalar hastaya ve hastalığa özgü tıbbi beslenme önerileri açııından da yararlı olabilir.

Anahtar sözcükler: Sekonder bileşikler, fenolik bileşikler, terpenler-steroidler, alkaloidler, kükürtlü bileşikler

\section{FUNCTIONAL EFFECTS OF PLANT SECONDARY METABOLITES ON HEALTH}

\section{ABSTRACT}

Some types of secondary compounds, which are generally classified into 4 groups as phenolic compounds, terpenes-steroids, alkaloids and organosulfur compounds are critical for both medicine and pharmacy since they show anti-inflammatory, hypoglycemic, hypolipidemic and antioxidant effects, have protective effects against cardiovascular diseases and cancer and have a variety of positive effects on health. It has been revealed that some phenolic compounds have cardioprotective effects by inhibiting the oxidation of lipoproteins, exhibiting hypocholesterolemic effect, reducing atherosclerosis risk, inhibiting platelet aggregation, improving vascular function, protecting the metabolism against inflammation and oxidative stress. Besides, some secondary compounds such as sulfurous compounds and flavonoids have beneficial effects on diabetes-related hyperglycemia and abnormal lipid profile and consequently, may be protective against diabetic neuropathy, diabetic nephropathy, and diabetic retinopathy. Some phenolic compounds and alkaloids have also been shown to demonstrate the anticarcinogenic activity by inhibiting carcinogenesis to DNA, having a protective effect against oxidative DNA damage, normalizing altered cell signaling leading to inhibition of malignant transformation, and inhibiting the growth and metastatic potential of cancer cells. A greater number of secondary metabolites have been discovered thanks to the development of bioreactor technology and the use of plant secondary metabolites has begun to be used more in drug production. However, rather than extract and nutraceutical forms of secondary metabolites, which are effective not only in the treatment of the diseases but also maintaining health and avoiding diseases, it may be more beneficial to consume natural forms of them with fruits and vegetables. The clinical course of a disease can be improved by recommending vegetables and fruits which are rich in secondary metabolites, whose functional activity is known in the medical nutritional recommendations for diseases. Studies evaluating the functional efficacy of different secondary metabolites against diseases may also be useful in terms of patient and disease-specific medical nutrition recommendations.

Keywords: Secondary compounds, phenolic compounds, terpenes-steroids, alkaloids, organosulfur compounds 
Ditki kimyasalları genellikle primer ve sekonder metabolitler olarak ikiye ayrılır. Primer metabolitler (protein, karbonhidrat, yağ, vitamin); canlılar için büyüme, metabolizma faaliyetleri ve üreme gibi yaşamsal faaliyetlerde rol alırken, sekonder metabolitler (fenolik bileşikler, terpenler-steroidler, alkaloidler, kükürtlü bileşikler); primer metabolitlerden biyosentetik yolla üretilir ve canlının temel yaşamsal işlevleri ile doğrudan ilişkisi olmayan biyolojik süreçlerde rol alırlar. Sekonder metabolitlerin canlının yaşamsal fonksiyonlarında doğrudan rolü olmasa da sağlığın korunmasında ve sürdürülmesinde önemli rolleri vardır ve günümüzde birçok sektörde hammadde olarak kullanılmaktadır (1). Biyoaktif özellikli kimyasal bileşikler olan sekonder metabolitler özellikle tıp ve eczacılık alanlarında sıklıkla kullanılsa da, fonksiyonel gıda bileşeni ve besin takviyesi olarak kullanılabilmeleri dolayısıyla da önemlidir (2). Illk kez 1891'de tanımlanan sekonder metabolitler (3) kimyasal yapılarına, kompozisyonlarına ve bazı çözücülerdeki çözünürlük durumlarına göre farklı şekillerde sınıflandırılabilse de İngiliz Beslenme Vakfı (British Nutrition Foundation) tarafından dört ana kategoriye ayrııır ve Şekil 1'deki gibi sınıflandırıı (4).

Günümüzde özellikle ilaç yapımında önemli hale gelen sekonder bileşiklerin bazı türlerinin antiinflamatuar, hipoglisemik, hipolipidemik ve antioksidan etki gösterdiği belirtilmiştir. Ayrıca bazı sekonder bileşiklerin de trombozis ve kansere karşı da koruyucu olduğu belirtilmiştir. Mevcut bu özelliklerinden dolayı sekonder bileşiklerin obezite, diyabet, metabolik sendrom, dislipidemi, kardiyovasküler hastalıklar ve kanser gibi bazı hastalıklara karşı koruyucu olabileceği düşünülmektedir.

\section{Antiinflamatuar etki}

İnflamatuar süreç, vücudun yaralanma ve tehlikeye verdiği yanıttır ve enfeksiyöz ajanlar, iskemi, antijen-antikor etkileşimi, termal veya fiziksel hasar gibi birçok uyaran tarafından ortaya çıkabilen bir dizi olayı içerir (5). Hücresel

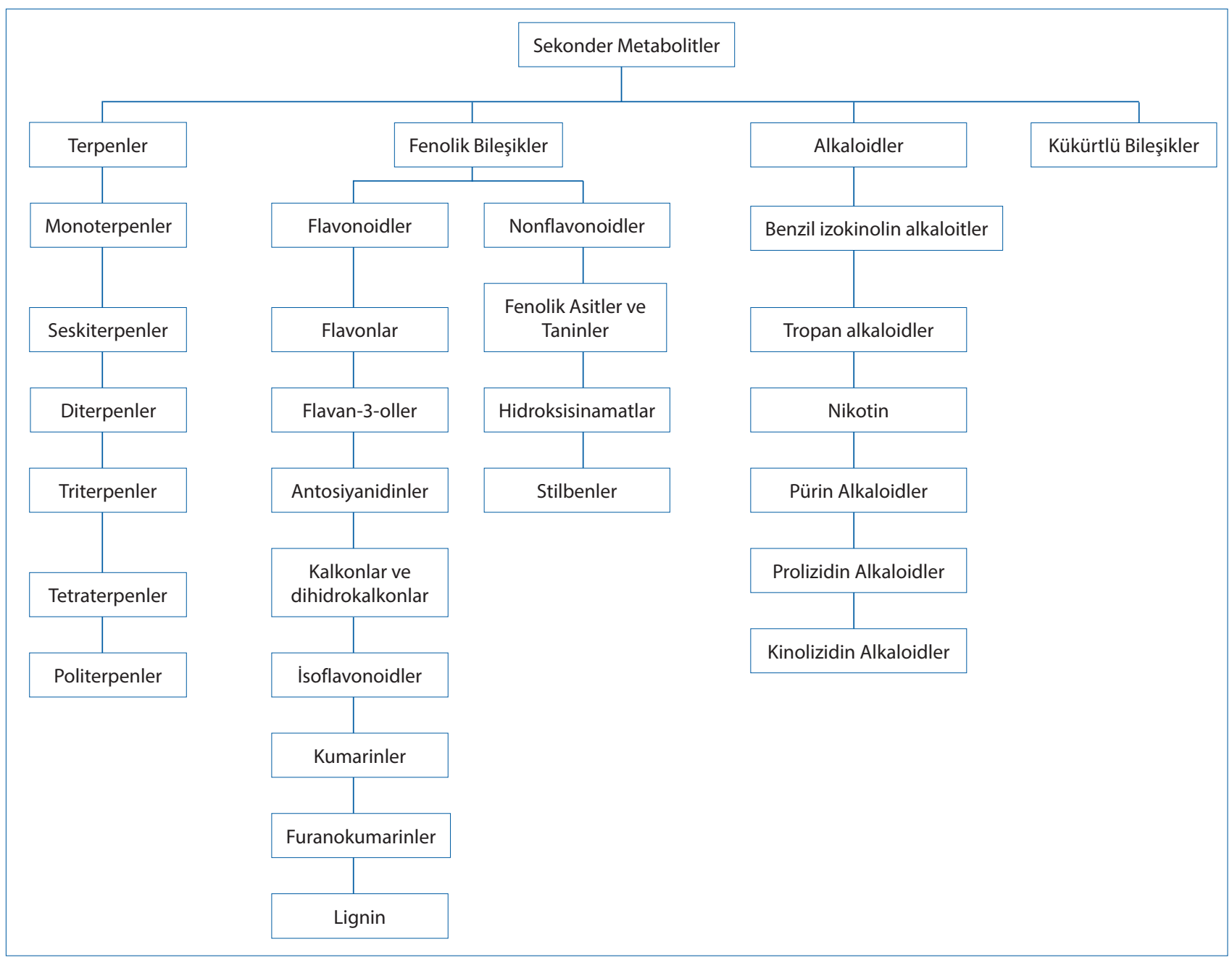

Şekil 1. Sekonder metabolitlerin genel sınıflandırıması 
tahribat ile sonuçlanan uzamış, düzensiz ve uyumsuz bir tepki olarak tanımlanan kronik inflamasyon astım, ateroskleroz, obezite, diyabet, kanser, nörodejenaratif hastalıklar ve otoimmün hastalıklar gibi birçok kronik hastalık ile ilişkilidir (6). İnflamasyona ilişkin olarak birçok nonsteroidal antiinflamatuar ajan geliştirilse de bu ajanların gastrointestinal irritasyon, trombosit disfonksiyonu ve nefrotoksisite gibi olumsuz etkilerinin ortaya çıkması dolayısıyla yeni güvenli antiinflamatuar öncü bileşiklerin keşfi büyük önem taşımaktadır (7). Bu bağlamda bitkisel sekonder metabolitlerin antiinflamatuar etkinliği çalışmalarda sıklıkla araştırımaktadır. Antiinflamatuar etkinliği bulunan sekonder metabolitlerin, antioksidan ve serbest radikal temizleyici aktivite göstererek, inflamasyona ilişkin hücresel mekanizmaları regüle ederek, fosfolipaz A2, siklooksigenaz, lipoksigenaz, nitrik oksit sentaz gibi enzim aktivitelerini ve proinflamatuar gen ekspresyonunu modüle ederek, proinflamatuar sitokinlerin salınımını azaltarak antiinflamatuar etki gösterdiği belirtilmiştir $(6,8)$.

Antiinflamatuar etkinliği çalışılan 49 alkaloidden 40'ının antiinflamatuar etki gösterdiği belirtilmiştir. İzokinolin, kinolin ve indol alkaloidler antiinflamatuar etkinliği en fazla çalışılan alkaloidler olmuştur (9). Diterpenoidlerin çeşitli inflamatuar hastalıklarda karakteristik bir fenomen olan ve vücudun inflamatuar tepkisinde rol oynayan nükleer faktör-kappaB (NF-KB) gibi kritik hücre sinyal yollarını modüle ettiği belirtilmiştir (10). Farklı bir çalışmada da benzer şekilde triterpenoidlerin NF-KB aktivasyonunu inhibe ettiği bununla birlikte tümör nekrozis faktör-alfa, interlökin 1 beta, interlökin 6 ve interlökin 10 gibi proinflamatuar sitokinlerin salınımını da azalttığı saptanmıştır (5). Çemen otu tohumlarının metanolik ekstraktlarının antiinflamatuar etkinliğinde alkaloid ve flavonoid içeriğinin etkisinin olabileceği belirtilmiştir (11).

Genistein, kaempferol, kuersetin ve daidzein gibi flavonoidlerin sinyal iletici ve transkripsiyon 1 aktivatörü (STAT1), indüklenebilir Nitrik Oksit Sentaz (iNOS) ve NF-kB düzeylerini inhibe ederek inflamasyona karşı koruduğu belirtilirken isorhamnetin, naringenin ve pelargonidin gibi flavonoidlerin ise yalnızca NF-KB aktivasyonunu inhibe ederek inflamasyona karşı koruduğu belirtilmiştir (12). Deneysel inflamasyon modellerinde flavonol (kuersetin, rutin ve morin) ve flavanonların (hesperetin ve hesperidin) inflamasyon üzerine etkinliği araştırıldığında, ksilen aracıllğılla yapılan nörojenik inflamasyonda flavanonların (hesperetin ve hesperidin) etkili olduğu belirtilirken rutinin ise kronik inflamasyonda etkili olduğu saptanmıştır (13). İzoflavon (daidzin, glisitin, genistein ve bunların glikozitleri) içeren diyetlerin intraperitonel lipopolisakkarit enjeksiyonu yapılmış farelerde proinflamatuar sitokinlerin ve
STAT3 salınımını inhibe ederek inflamasyona karşı koruduğu belirtilmiştir (14). Fang ve ark.'nın (15) yapmış olduğu çalışmada artokarpesin (flavon), norartokarpetin (flavon) ve oksiresveratrolün (stilben) antiinflamatuar etki gösterdiği belirtilirken artokarpesinin iNOS ve siklooksijenaz 2 (COX-2) protein ekspresyonunu aşağı yönlü regüle ederek lipopolisakkarit enjeksiyonundan kaynaklanan nitrik oksit ve prostaglandin $\mathrm{E}_{2}$ üretimini baskıladığı belirtilmiştir.

\section{Antidiyabetik etki}

Diabetes mellitus (DM) insülin sekresyonu ya da etkisindeki defektler nedeniyle organizmanın karbonhidrat, yağ ve proteinden yeterince yararlanamadığı, hiperglisemi ile karakterize kronik metabolik bir hastalıktır (16). Dünyada en fazla görülen kronik hastalıkların başında gelen ve pandemi olarak nitelendirilen DM tedavisinin en önemli kısımlarından birisi de tıbbi beslenme tedavisidir. Tıbbi beslenme tedavisinde hastanın enerji ve besin ögesi ihtiyacını karşılamak kadar diyabete ilişkin fonksiyonel etkinliği bulunan besinsel ögelerinin de diyette yer alması önemlidir. Son birkaç yılda bitkilerdeki sekonder bileşiklerin izole edilmesiyle elde edilen bazı biyoaktif ilaçların oral hipoglisemik ajanlardan daha etkili olduğu belirtilmiştir (17).

Sağlıklı bireylerde flavonoid içeriği yüksek gıdaların tüketiminin artırımasının diyabet riskini azaltabileceği, diyabetik bireylerde ise diyabete ilişkin komplikasyonların gelişim sürecini yavaşlatabileceği veya engelleyebileceği belirtilmiştir (18). Deneysel diyabet oluşturulmuş ratlarda farklı bitkilerden izole edilen flavonoidlerin kan glukoz düzeylerini (19-21), HbA1 c düzeylerini azalttığı $(22,23)$ ve lipid profilini iyileştirdiği $(24,25)$ görülmüştür. Ayrıca bazı flavonoidlerin diyabetik ratlarda karbonhidrat metabolizmasında görevli hekzokinaz, piruvat kinaz, laktat dehidrogenaz, glukoz-6fosfotaz, fruktoz-1.6-difosfataz, glikoz-6-fosfat dehidrogenaz enzim aktivitelerini artırarak glikolizisi artırdığı ve glikoneogenezi azalttığı belirtilirken (23), yüksek yağlı yemle beslenen diyabetik ratlarda da insülin duyarlııı̆ını artırdığı belirtilmiştir (26). Cho ve ark.'nın (27) yapmış olduğu çalışmada ise doza paralel olarak daidzein'in glukoz transporter 4 ve insülin reseptör substrat- 1 aktivitesini artırarak glikoz kullanımını artırdığı belirtilmiştir. Genellikle antibiyotik ilaçların yapımında kullanılan bir alkaloid olan berberinin açlık ve tokluk plazma glikoz düzeylerinin yanısıra $\mathrm{HbA} 1$ c düzeyini azaltmada ve plazma lipid profilini düzeltmede etkili olduğu saptanmıştır (28).

Sekonder metabolitlerin yalnızca diyabete bağlı olarak görülen hiperglisemi ve bozulmuş lipid profiline karşı değil, diyabetik nöropati, diyabetik nefropati, diyabetik 
retinopati ve diyabete bağlı olarak görülen kardiyovasküler hastalıklara karşıda olumlu etkileri bulunmaktadır. Kuersetinin (29) ve diosminin (19) diyabetik nöropatiye karşı koruyucu olabileceği belirtilirken, yüksek flavonoid içerikli meyve ve sebze tüketiminin de diyabetik retinopati riskini \%30 azalttığı belirtilmiştir. Ayrıca puerarinin diyabetik sıçanlarda peroksinitrit düzeyini ve iNOS ekspresyonunu azaltarak retina pigment epitelyal hücre apoptozunu azalttığı saptanmıştır (30). Garcinia kola bitkisinden ekstrakte edilen Kolaviron'un renal dokularda oksijen radikal absorbans kapasiteyi ve glutatyon konsantrasyonlarını artırarak ve renal interlökin-1 seviyesini suprese ederek diyabetik nefropatiye karşı koruyucu olabileceği belirtilmiştir (31). Bunun yanısıra farklı sekonder bileşiklerinde renal fonksiyona ilişkin parametrelerde iyileşme sağladığı bildirilmiştir $(32,33)$.

\section{Kardioprotektif etki}

Kardiyovasküler hastalıklar dünyada ölüm ve hastalıkların birincil nedenidir. Türkiye İstatistik Kurumunun hazırladığı ölüm nedeni istatistiklerine göre Türkiye'de ölüm vakalarının \%39,8'inin dolaşım sistemi hastalıklarından kaynaklandığı belirtilirken (34), Dünya Sağlık Örgütünün verilerine göre dünyadaki tüm ölümlerin yaklaşık \%31'inin kardiyovasküler hastalıklardan kaynaklandığını belirtmiştir (35). Bu ölümlere en büyük etken düzensiz yaşam tarzı alışkanlıklarının ve sağlıksız beslenme alışkanlıklarının artmasıdır. Kardiyovasküler hastalıklara ilişkin risk faktörlerinin çoğu değiştirilebilir risk faktörleri olup, sağlıklı beslenme alışkanlıkları ve sağlıklı yaşam tarzı değişiklikleri gibi nonfarmakolojik tedbirler hastalığa ilişkin risk faktörlerinin kontrol altına alınmasını sağlayabilir. Kardiyovasküler hastalıklara karşı koruyucu olduğu bilinen sekonder bileşikleri intiva eden sebze ve meyvelere günlük diyette yer vermek önemli nonfarmakolojik tedbirlerden birisidir. Sağlıkı bir diyetin önemli bir parçası olan sebzelerin tüketiminin artmasının kardiyovasküler hastalıklara bağlı mortalite oranlarını düşürdüğü (36), risk faktörlerini ise iyileştirdiği belirtilmiştir (37). Özellikle fenolik bileşikler kardiyoprotektif etkinliği olduğu düşünülen sekonder bileşiklerdir. Fransız paradoksuna göre Fransızlarda yüksek doymuş yağ alımına, yüksek kan kolesterol düzeylerine ve yüksek kan basıncına rağmen kardiyovasküler hastalıklara bağlı ölüm oranının az olmasının sebebi, fazla şarap tüketimine bağlı olarak fazla resveratrol alımıyla ilişkilendirilmiştir (38). Resveratrol iskemi-reperfüzyon sırasında miyokardiyal hasarı azaltarak, vasküler hücre fonksiyonlarını modüle ederek, LDL oksidasyonunun inhibisyonu ve trombosit agregasyonunu baskılayarak kardiyovasküler sağlığı korur (39). Ayrıca nitrik oksit sentaz üretimini etkileyerek vazodilatör, lipidlerin peroksidasyon son ürünü olan malondialdehidin seviyesini azaltarak da antioksidan etki gösterir (40). Resveratrol dışında farklı fenolik bileşiklerin de lipoproteinlerin oksidasyonunu önleyerek, hipokolesterolemik etki göstererek, aterosklerozis riskini azaltarak, platelet agregasyonunu inhibe ederek, vasküler fonksiyonu iyileştirerek, inflamasyon ve oksidatif strese karşı koruyarak kardiyoprotektif etki gösterdiği belirtilmiştir $(41,42)$.

Kükürtlü bileşikler de kardiyoprotektif etkinliği olduğu düşünülen sekonder bileşiklerdendir. Literatürdeki çalışmalarda soğan ve sarımsakta bulunan kükürtlü bileşiklerin kolesterol ve yağ asidi sentezinde rol alan kilit enzimleri (monooksijenaz, HMG-KoA redüktaz) inhibe ederek kolesterol ve lipid düşürücü (43), siklooksijenaz enzim aktivitesini inhibe ederek antiplatelet etki (44), oksitlenmiş eritrositlerde lipid peroksidasyonunu ve hemolizi önleyerek fibrinolitik etki gösterdiği belirtilmiştir (45). Ayrıca bu bileşiklerin hücre içi nitrik oksit ve hidrojen sülfit üretimini uyararak, anjiyotensin konverting enzim aktivitesini inhibe ederek kan basıncını düşürücü etki gösterdiği bildirilmiştir (46). Kardiyovasküler hastalıkların patogenezinde önemli rolü olduğu düşünülen reaktif oksijen türlerinin de soğan ve sarımsakta bulunan kükürtlü bileşikler sayesinde azaldığı, antioksidan kapasitenin ise arttığı görülmüştür $(47,48)$.

\section{Antikarsinojenik etki}

Bir organ veya dokudaki hücrelerin düzensiz olarak bölünüp çoğalmasıyla beliren kötü urlar olarak tanımlanan kanser, dünyada ölümün ana nedenleri arasında yer alır ve her altı ölümden birinin kanserden kaynaklandığı belirtilmektedir (49). Kanserden kaynaklanan ölümlerin yaklaşık üçte biri, 5 temel davranışsal ve diyetsel faktörden kaynaklanmaktadır. Bu faktörler; yüksek beden kütle indeksi, düşük meyve ve sebze tüketimi, fiziksel aktivite eksikliği, tütün kullanımı ve alkol kullanımıdır. Bu risk faktörlerinin düzenlenmesiyle kansere bağlı ölümlerin $\% 30$ ile $\% 50$ oranında azaltılabileceği belirtilmiştir (49). Yeterli sebze ve meyve tüketiminin içeriğindeki sekonder bileşiklerden dolayı kansere karşı koruyucu olabileceği düşünülmekte ve bitki ekstraktlarına da kanser tedavisinde sıklıkla başvurulabilmektedir. Bazı çalışmalarda bitki ekstraktlarının sentetik bileşiklere göre daha fazla antikanser etki gösterdiği belirtilse de hangi bileşiklerin kanser hücreleri üzerinde etkili olduğunu veya bu etkinin bitki sekonder metabolitleri arasındaki sinerjiden kaynaklanıp kaynaklanmadığını belirlemek zordur. Fakat günümüzde kanser ilaçlarının \%60'ından fazlası doğal bileşiklerden üretilmektedir ve bu nedenle kanser tedavisinde bitki sekonder metabolitleri büyük bir önem arz etmektedir $(50,51)$. 
Fenolik bileşikler kemopreventif ve kemoterapötik etkinliği en fazla çalışılan sekonder bileşiklerden olup, güncel çalışmalar çeşitli alt gruplardan fenolik bileşiklerin, farklı kanser hücrelerinin proliferasyonunu önemli ölçüde inhibe ettiğini göstermektedir (52). Flavonoidlerden kuersetinin servikal kanser hücrelerinde p53 ve p21 ekspresyonunu artırarak ve hücre proliferasyon markerlerinden siklin D1 ekspresyonunu azaltarak (53), kolon kanser hücrelerinde siklin D1 ve survivin ekspresyonunu azaltarak ve Wnt/ $\beta$-katenin sinyal yolunu suprese ederek (54), meme kanser hücrelerinde $\mathrm{p} 53$ ve $\mathrm{p} 57$ proteinlerinin ekspresyonunu artırarak ve siklin A, siklin B siklin bağımlı kinaz 2 protein ekspresyonunu azaltarak antiproliferatif etki gösterdiği belirtilmiştir (55). Resveratrolün karaciğer ve yumurtalık kanser hücrelerinde siklin D1 ekspresyonunu azaltarak kanser hücrelerinin büyümesini inhibe ettiği saptanmıştır (56). Ayrıca flavonlardan luteolinin nazofaringeal ve kolon kanseri hücrelerinde p21, survivin ve siklin D1 ekspresyonunu azalttığı ve bu nedenle kansere karşı koruyucu olabileceği ifade edilmiştir $(57,58)$. Daidzein'in meme kanseri hücrelerinde siklin $D$, siklin bağımlı kinaz 2, siklin bağımlı kinaz 1 ve siklin bağımlı kinaz 4 seviyelerini azaltarak, p21 ve p57 konsantrasyonlarını artırarak antiproliferatif etki gösterdiği belirtilmiştir (59). Literatürde sekonder bileşiklerin kanser üzerine etkilerinin değerlendirildiği çalışmalar genellikle spesifik hücre kültürleri ile yapılan in vitro çalışmalar olsa da 200 mg/gün düzeyinde fitoöstrojen alımının hormon bağımlı kanser riskini azalttığı belirtilmiştir (41). Lignan açısından zengin diyetin de postmenopozal kadınlarda azalmış meme kanseri riski ile ilişkili olabileceği (60) ve meme kanseri olan kadınlarda sağ kalım oranlarını arttırabileceği belirtilmiştir (61). Ayrıca kuarsetin, kateşin, kumarin ve warfarin gibi sekonder bileşiklerin antitümör aktivitesinden dolayı kansere karşı koruyucu olabileceği belirtilmiştir (50). Alkaloidlerden vinblastin ve vinkristin

\section{Kaynaklar}

1. Babaoğlu M, Gürel E, Özcan S. Bitki Biyoteknolojisi I. Doku Kültürü ve Uygulamaları. Konya: Selçuk Üniversitesi Vakfı Yayınları; 2001. ss.211-61.

2. Güven $A$, Gürsul I. Bitki doku kültürlerinde sekonder metabolit sentezi. Gıda / J Food 2014;39:299-306. [CrossRef]

3. Bourgaud F, Gravot A, Milesi S, Gontier E. Production of plant secondary metabolites: a historical perspective. Plant Sci 2001;161:839-51. [CrossRef]

4. Ahmad E, Arshad M, Khan MZ, Amjad MS, Sadaf HM, Riaz I, et al. Secondary metabolites and their multidimensional prospective in plant life. Journal Of Pharmacognosy And Phytochemistry 2017;6:205-14. http://www.phytojournal.com/archives/2017/ vol6issue2/PartC/6-2-2-130.pdf

5. Yan $M$, Zhu $Y$, Zhang $H J$, Jiao $W H$, Han BN, Liu ZX, et al. Antiinflammatory secondary metabolites from the leaves of Rosa laevigata. Bioorg Med Chem 2013;21:3290-7. [CrossRef] kansere karşı etkinliği olduğu düşünülen sekonder bileşiklerdendir ve yaklaşık 40 yıldır anti-kanser ilaçların yapımında kullanılmaktadır (62).

Sonuç olarak bitki sekonder bileşikleri DNA'ya karsinojen bağlanmasını inhibe ederek, oksidatif DNA hasarına karşı koruyarak, malign dönüşümün inhibisyonuna yol açan değiştirilmiş hücre sinyallemesini normalize ederek, kanser hücresinin büyümesini ve metastatik potansiyelini inhibe ederek antikarsinojenik etki gösterir (62).

\section{Sonuç}

Diyabet, kanser ve kardiyovasküler hastalıklara karşı koruyucu olması, antiinflamatuar ve antioksidan etkinlik göstermesi dolayısıyla sağlık açısından önemli olan sekonder bileşiklere olan ilgi her geçen gün artmaktadır. Tıp ve eczacılık başta olmak üzere birçok alanda kullanılan sekonder metabolitler yalnızca hastalıkların tedavisinde değil, sağlığın sürdürülmesi ve hastalıklara karşı korunmada da etkilidir. Özellikle bitkisel nutrasötiklerin yapımında kullanılan sekonder metabolitlerin literatürdeki çalışmalarca birçok hastalığa karşı olumlu etkinlik gösterdiği belirtilse de, güvenilir alım düzeyine ilişkin olarak sağlık otoritelerince belirlenmiş herhangi bir öneri bulunmamaktadır. Sağlığa verilen önemin artmasıyla birlikte insanlar geleneksel tedavi yöntemlerine daha fazla önem verebilmekte ve nutrasötikleri bilinçsiz olarak kullanabilmektedir. Dolayısıyla sekonder metabolitlerin güvenilir alım düzeylerinin ve fonksiyonel etkinliğinin klinik çalışmalarla değerlendirilmesi önem arz etmektedir. Ayrıca hastalıklara karşı fonksiyonel etkinliği kanıtlanmış olan sekonder bileşiklerin ekstrakte ve nutrasötik formlarından ziyade meyve ve sebzelerle birlikte doğal formlarının alınması sekonder bileşiklerin sinerjistik etkinliğinden daha fazla yararlanılmasını ve muhtemel toksik riskin azaltılmasını sağlayabilir.

6. García-Lafuente A, Guillamón E, Villares A, Rostagno MA, Martínez JA. Flavonoids as anti-inflammatory agents: implications in cancer and cardiovascular disease. Inflamm Res 2009;58:537-52. [CrossRef]

7. Yoon JH, Baek SJ. Molecular targets of dietary polyphenols with antiinflammatory properties. Yonsei Med J 2005;46:585-96. [CrossRef]

8. Mohammed MS, Osman WJ, Garelnabi EA, Osman Z, Osman B, Khalid HS, Mohamed MA. Secondary metabolites as antiinflammatory agents. J Phytopharmacol 2014;3:275-85. http:// www.phytopharmajournal.com/Vol3_Issue4_09.pdf

9. Souto AL, Tavares JF, Da Silva MS, Diniz MF, De Athayde-Filho PF, Barbosa FJM. Anti-inflammatory activity of alkaloids: an update from 2000 to 2010. Molecules 2011;16:8515-34. [CrossRef]

10. De las Heras $B$, Hortelano S. Molecular basis of the anti-inflammatory effects of terpenoids. Inflamm Allergy Drug Targets 2009;8:28-39. [CrossRef] 
11. Mandegary A, Pournamdari M, Sharififar F, Pournourmohammadi S, Fardiar R, Shooli S. Alkaloid and flavonoid rich fractions of fenugreek seeds (Trigonella foenum-graecum L.) with antinociceptive and anti-inflammatory effects. Food Chem Toxicol 2012;50:2503-7. [CrossRef]

12. Hämäläinen $M$, Nieminen $R$, Vuorela $P$, Heinonen $M$, Moilanen E. Antiinflammatory effects of flavonoids: genistein, kaempferol, quercetin, and daidzein inhibit STAT-1 and NF-KB activations, whereas flavone, isorhamnetin, naringenin, and pelargonidin inhibit only NF-KB activation along with their inhibitory effect on iNOS expression and NO production in activated macrophages. Mediators Inflamm 2007;2007:45673. [CrossRef]

13. Rotelli $A E$, Guardia $T$, Juárez $A O$, de la Rocha NE, Pelzer LE. Comparative study of flavonoids in experimental models of inflammation. Pharmacol Res 2003;48:601-6. [CrossRef]

14. Paradkar PN, Blum PS, Berhow MA, Baumann H, Kuo SM. Dietary isoflavones suppress endotoxin-induced inflammatory reaction in liver and intestine. Cancer Lett 2004;215:21-8. [CrossRef]

15. Fang SC, Hsu CL, Yen GC. Anti-inflammatory effects of phenolic compounds isolated from the fruits of Artocarpus heterophyllus. J Agric Food Chem 2008;56:4463-8. [CrossRef]

16. American Diabetes Association. Diagnosis and Classification of Diabetes Mellitus. Diabetes Care 2014;37:S81-90. [CrossRef]

17. Malviya N, Jain S, Malviya S. Antidiabetic potential of medicinal plants. Acta Pol Pharm 2010;67:113-8. https://www.ptfarm.pl/pub/ File/Acta_Poloniae/2010/2/113.pdf

18. Vinayagam $R, X u$ B. Antidiabetic properties of dietary flavonoids: a cellular mechanism review. Nutr Metab (Lond) 2015;12:60. [CrossRef]

19. Jain D, Bansal MK, Dalvi R, Upganlawar A, Somani R. Protective effect of diosmin against diabetic neuropathy in experimental rats. J Integr Med 2014;12:35-41. [CrossRef]

20. Alam MM, Meerza D, Naseem I. Protective effect of quercetin on hyperglycemia, oxidative stress and DNA damage in alloxan induced type 2 diabetic mice. Life Sci 2014;109:8-14. [CrossRef]

21. Akiyama S, Katsumata SI, Suzuki K, Nakaya Y, Ishimi Y, Uehara $M$. Hypoglycemic and hypolipidemic effects of hesperidin and cyclodextrin-clathrated hesperetin in Goto-Kakizaki rats with type 2 diabetes. Biosci Biotechnol Biochem 2009;73:2779-82. [CrossRef]

22. Kakadiya J, Mulani $H$, Shah N. Protective effect of hesperidin on cardiovascular complication in experimentally induced myocardial infarction in diabetes in rats. J Basic Clin Pharm 2010;1:85-91. https://www.ncbi.nlm.nih.gov/pmc/articles/PMC3979178/

23. Prasath GS, Subramanian SP. Modulatory effects of fisetin, a bioflavonoid, on hyperglycemia by attenuating the key enzymes of carbohydrate metabolism in hepatic and renal tissues in streptozotocin-induced diabetic rats. Eur J Pharmacol 2011;668:4926. [CrossRef]

24. Niture NT, Ansari AA, Naik SR. Anti-hyperglycemic activity of rutin in streptozotocin-induced diabetic rats: an effect mediated through cytokines, antioxidants and lipid biomarkers. Indian J Exp Biol 2014;52:720-7.

25. Prasath GS, Subramanian SP. Antihyperlipidemic Effect of Fisetin, a Bioflavonoid of Strawberries, Studied in Streptozotocin-Induced Diabetic Rats. J Biochem Mol Toxicol 2014;28:442-9. [CrossRef]

26. Sendrayaperumal V, Iyyam Pillai S, Subramanian S. Design, synthesis and characterization of zinc-morin, a metal flavonol complex and evaluation of its antidiabetic potential in HFD-STZ induced type 2 diabetes in rats. Chem Biol Interact 2014;219:9-17. [CrossRef]

27. Cho KW, Lee OH, Banz WJ, Moustaid-Moussa N, Shay NF, Kim YC. Daidzein and the daidzein metabolite, equol, enhance adipocyte differentiation and PPARy transcriptional activity. J Nutr Biochem 2010;21:841-7. [CrossRef]
28. Zhang Y, Li X, Zou D, Liu W, Yang J, Zhu N, et al. Treatment of type 2 diabetes and dyslipidemia with the natural plant alkaloid berberine. $J$ Clin Endocrinol Metab 2008;93:2559-65. [CrossRef]

29. Shi Y, Liang XC, Zhang H, Wu QL, Qu L, Sun Q. Quercetin protects rat dorsal root ganglion neurons against high glucose-induced injury in vitro through Nrf-2/HO-1 activation and NF-KB inhibition. Acta Pharmacol Sin 2013;34:1140-8. [CrossRef]

30. Hao LN, Wang M, Ma JL, Yang T. Puerarin decreases apoptosis of retinal pigment epithelial cells in diabetic rats by reducing peroxynitrite level and iNOS expression. Sheng Li Xue Bao 2012;64:199-206. http://www.actaps.com.cn/qikan/manage/wenzhang/2012-2-13. pdf

31. Ayepola OR, Cerf ME, Brooks NL, Oguntibeju OO. Kolaviron, a biflavonoid complex of Garcinia kola seeds modulates apoptosis by suppressing oxidative stress and inflammation in diabetes-induced nephrotoxic rats. Phytomedicine 2014;21:1785-93. [CrossRef]

32. Bao L, Zhang Z, Dai X, Ding Y, Jiang Y, Li Y, Li Y. Effects of grape seed proanthocyanidin extract on renal injury in type 2 diabetic rats. Mol Med Rep 2015;11:645-52. [CrossRef]

33. Park CH, Noh JS, Fujii H, Roh SS, Song YO, Choi JS, et al. Oligonol, a low-molecular-weight polyphenol derived from lychee fruit, attenuates gluco-lipotoxicity-mediated renal disorder in type 2 diabetic db/db mice. Drug discoveries \& therapeutics 2015;9, 13-22. [CrossRef]

34. Türkiye İstatistik Kurumu. Ölüm Nedeni İstatistikleri. www.tuik.gov. tr/PdfGetir.do?id=24572

35. World Health Organization. Cardiovascular Diseases Key Facts. http://www.who.int/news-room/fact-sheets/detail/ cardiovascular-diseases-(cvds)

36. Wang X, Ouyang Y, Liu J, Zhu M, Zhao G, Bao W, Hu FB. Fruit and vegetable consumption and mortality from all causes, cardiovascular disease, and cancer: systematic review and dose-response metaanalysis of prospective cohort studies. BMJ 2014;349:g4490. [CrossRef]

37. Radhika G, Sudha V, Sathya RM, Ganesan A, Mohan V. Association of fruit and vegetable intake with cardiovascular risk factors in urban south Indians. Br J Nutr 2008;99:398-405. [CrossRef]

38. Biagi M, Bertelli AA. Wine, alcohol and pills: What future for the French paradox? Life Sci 2015;131:19-22. [CrossRef]

39. Wu JM, Wang ZR, Hsieh TC, Bruder JL, Zou JG, Huang YZ. Mechanism of cardioprotection by resveratrol, a phenolic antioxidant present in red wine. Int J Mol Med 2001;8:3-17. [CrossRef]

40. Pektaş A, Pektaş MB, Koca HB, Tosun M, Aslan E, Koca S, Sadi G. Effects of resveratrol on diabetes-induced vascular tissue damage and inflammation in male rats. Turkish Journal of Biochemistry 2017;42:451-8. [CrossRef]

41. Singh B, Bhat TK, Singh B. Potential therapeutic applications of some antinutritional plant secondary metabolites. J Agric Food Chem 2003;51:5579-97. [CrossRef]

42. Rangel-Huerta OD, Pastor-Villaescusa B, Aguilera CM, Gil A. A systematic review of the efficacy of bioactive compounds in cardiovascular disease: phenolic compounds. Nutrients 2015;7:5177-216. [CrossRef]

43. Yeh YY, Liu L. Cholesterol-lowering effect of garlic extracts and organosulfur compounds: human and animal studies. J Nutr 2001;131:989S-93S. [CrossRef]

44. Chang HS, Yamato O, Yamasaki M, Maede Y. Modulatory influence of sodium 2-propenyl thiosulfate from garlic on cyclooxygenase activity in canine platelets: possible mechanism for the antiaggregatory effect. Prostaglandins Leukot Essent Fatty Acids 2005;72:351-5. [CrossRef]

45. Moriguchi T, Takasugi N, Itakura Y. The effects of aged garlic extract on lipid peroxidation and the deformability of erythrocytes. J Nutr 2001;131:1016S-9S. [CrossRef] 
46. Ried K, Frank OR, Stocks NP. Aged garlic extract reduces blood pressure in hypertensives: a dose-response trial. Eur J Clin Nutr 2013:67:64-70. [CrossRef]

47. Azuma K, Minami Y, Ippoushi K, Terao J. Lowering effects of onion intake on oxidative stress biomarkers in streptozotocin-induced diabetic rats. J Clin Biochem Nutr 2007;40:131-40. [CrossRef]

48. Lee YM, Gweon OC, Seo YJ, Im J, Kang MJ, Kim MJ, Kim JI. Antioxidant effect of garlic and aged black garlic in animal model of type 2 diabetes mellitus. Nutr Res Pract 2009;3:156-61. [CrossRef]

49. World Health Organization. Cancer Key Facts. http://www.who.int/ en/news-room/fact-sheets/detail/cancer

50. Carocho M, Ferreira, IC. The role of phenolic compounds in the fight against cancer-a review. Anticancer Agents Med Chem 2013;13:1236-58. [CrossRef]

51. Sharangi AB. Secondary Metabolites in Spices and Medicinal Plants: An Overview. In: Siddiqui MW, Bansal V, Prasad K, editors. Plant Secondary Metabolites. Florida, US: Apple Academic Press; 2017. pp.163-88.

52. Jafari S, Saeidnia S, Abdollahi M. Role of natural phenolic compounds in cancer chemoprevention via regulation of the cell cycle. Curr Pharm Biotechnol 2014;15:409-21. [CrossRef]

53. Priyadarsini RV, Murugan RS, Maitreyi S, Ramalingam K, Karunagaran $D$, Nagini S. The flavonoid quercetin induces cell cycle arrest and mitochondria-mediated apoptosis in human cervical cancer (HeLa) cells through p53 induction and NF-KB inhibition. Eur J Pharmacol 2010;649:84-91. [CrossRef]

54. Shan BE, Wang MX, Li RQ. Quercetin inhibit human SW480 colon cancer growth in association with inhibition of cyclin D1 and survivin expression through $\mathrm{Wnt} / \beta$-catenin signaling pathway. Cancer Invest 2009;27:604-12. [CrossRef]
55. Jeong JH, An JY, Kwon YT, Rhee JG, Lee YJ. Effects of low dose quercetin: Cancer cell-specific inhibition of cell cycle progression. J Cell Biochem 2009;106:73-82. [CrossRef]

56. Parekh P, Motiwale L, Naik N, Rao KV. Downregulation of cyclin D1 is associated with decreased levels of p38 MAP kinases, Akt/PKB and Pak1 during chemopreventive effects of resveratrol in liver cancer cells. Exp Toxicol Pathol 2011;63:167-73. [CrossRef]

57. Ong CS, Zhou J, Ong CN, Shen HM. Luteolin induces G1 arrest in human nasopharyngeal carcinoma cells via the Akt-GSK-3ß-Cyclin D1 pathway. Cancer Lett 2010;298:167-75. [CrossRef]

58. Lim DY, Jeong Y, Tyner AL, Park JH. Induction of cell cycle arrest and apoptosis in HT-29 human colon cancer cells by the dietary compound luteolin. Am J Physiol Gastrointest Liver Physiol 2007;292:66-75. [CrossRef]

59. Choi EJ, Kim GH. Daidzein causes cell cycle arrest at the $\mathrm{G} 1$ and G2/M phases in human breast cancer MCF-7 and MDA-MB-453 cells. Phytomedicine 2008;15:683-90. [CrossRef]

60. Buck K, Zaineddin AK, Vrieling A, Linseisen J, Chang-Claude J. Metaanalyses of lignans and enterolignans in relation to breast cancer risk. Am J Clin Nutr 2010;92:141-53. [CrossRef]

61. McCann SE, Thompson LU, Nie J, Dorn J, Trevisan M, Shields PG, et al. Dietary lignan intakes in relation to survival among women with breast cancer: the Western New York Exposures and Breast Cancer (WEB) Study. Breast Cancer Res Treat 2010;122:229-35. [CrossRef]

62. Korkina L, Kostyuk V. Biotechnologically produced secondary plant metabolites for cancer treatment and prevention. Curr Pharm Biotechnol 2012;13:265-75. [CrossRef] 